Full Paper

\title{
3D-Ensembles of Gold Nanowires: Preparation, Characterization and Electroanalytical Peculiarities
}

\author{
Manuela De Leo, ${ }^{\mathrm{a}, \mathrm{b}}$ Alexander Kuhn, ${ }^{\mathrm{b} *}$ Paolo Ugo ${ }^{\mathrm{a} *}$ \\ a Department of Physical Chemistry, University of Venice, Santa Marta 2137, 30123 Venezia, Italy \\ *e-mail: ugo@unive.it \\ b LACReM, Ecole National Supérieure de Chimie et de Physique de Bordeaux, 16 Avenue Pey Berland, 33607 Pessac, France \\ *e-mail: kuhn@enscpb.fr
}

Received: July 28, 2006

Accepted: November 22, 2006

\begin{abstract}
Nanoelectrode ensembles (NEEs) of gold nanodisks, prepared by electroless template deposition of gold within the pores of track-etched polycarbonate membranes, are treated with oxygen plasma or with solvent mixtures in order to achieve controlled etching of part of the polycarbonate of the template. This causes the structure of the final ensemble to change from a 2-D flat structure into a 3-D one. The cyclic voltammetric (CV) behavior of redox probes at the 3DNEEs is examined and compared with the behavior observed at 2D-NEEs. Finally, 3D-NEEs are examined in order to test possible applications for the development of mediated sensors.
\end{abstract}

Keywords: Nanoelectrodes, Nanowire, Electron transfer, Voltammetry, Sensors

DOI: 10.1002/elan.200603724

\section{Introduction}

Nanoelectrode ensembles (NEEs) were introduced some years ago by Menon and Martin [1] as advanced electroanalytical devices. This and following work [1-3] demonstrated that, thanks to their geometrical characteristics, NEEs showed improved signal to background ratios and better detection limits.

The NEEs are prepared by electroless plating of diskshaped Au electrode elements within the pores of a microporous track-etched polycarbonate (PC) template. The diameter of the pores in the template determines the diameter of Au-nanodisks (typically $30 \mathrm{~nm}$ ), while the density of the pores determines the number of Au-disk nanoelectrode elements per $\mathrm{cm}^{2}$ of NEE surface and, correspondingly, the average distance between the nanoelectrode elements. NEEs, indeed, behave as electrodes with a partially blocked surface (PBE) operating under total overlap diffusion conditions. According to the model elaborated by Amatore et al. [4], the current response at a $\mathrm{PBE}$ is identical to the response at a bare electrode of the same geometric area, but characterized by a smaller apparent rate constant for the heterogeneous electron transfer, which decreases as the coverage with the blocking agent increases. Such an apparent rate constant $\left(k_{\text {app }}^{\circ}\right)$ is related to the true standard heterogeneous transfer rate constant $\left(k^{\circ}\right)$ by the fraction of blocked surface $(\theta)$, according to the following relationship:

$k_{\text {app }}^{\circ}=k^{\circ}(1-\theta)$
Under total overlap diffusion conditions, $\theta=\left(A_{\mathrm{geo}}-A_{\text {act }}\right) /$ $A_{\text {geo, }}$, where $A_{\text {act }}$ is the active area (i.e., the overall surface of the nanoelectrodes) and $A_{\text {geo }}$ is the overall geometric area (nanoelectrodes and insulator).

Equation 1 can be easily converted into:

$k_{\text {app }}^{\circ}=k^{\circ} f$

where $f$ is the fractional electrode area, defined as:

$f=A_{\text {act }} / A_{\text {geo }}$

Notwithstanding their interesting behavior and related analytical advantages [5], ensembles of nanodisk electrodes can present some limitations with respect to their use as sensors with functionalized electrode surfaces. In fact, when immobilizing chemical reactants or electrocatalysts on the electrode surface one has to take into account the very low value of the active area of the ensemble, which can be $10^{2}-$ $10^{3}$ times smaller than the overall geometric area.

It was recently shown [6] that the small surface area of the nanodisk electrodes of an ensemble can be increased in a controlled way by suitable etching, in order to partially remove the upper layers of the PC template membrane. This causes the structure of the final ensemble to change from a flat 2-D surface, made of metal nanodisks imbedded into the $\mathrm{PC}$, to a 3-D structure made by an ensemble of gold nanowires partially protruding from the PC insulating layer. Such an approach is summarized in Scheme 1.

(C) 2007 WILEY-VCH Verlag GmbH \& Co. KGaA, Weinheim 


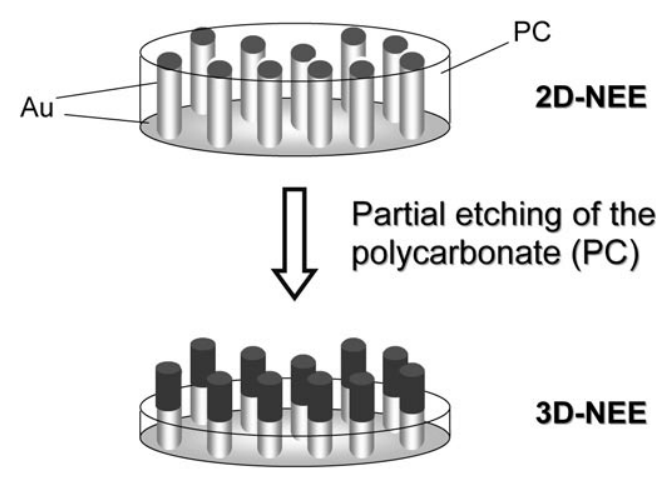

Scheme 1. Schematic drawing of the effect of the etching on the NEE structure.

Martin et al. [6] first proposed $\mathrm{O}_{2}$ plasma as a way for achieving the controlled removal of PC. This method was recently applied to the preparation of 3D-NEEs functionalized with ss-DNA for DNA sequencing [7,8]. These publications described enhanced electrocatalysis of redox reporters at DNA-modified 3D-NEEs. The authors suggested that the 3D-NEE architecture of the nanowires could facilitate the electrocatalytic reaction because of enhanced diffusion around the nanofibers.

Recently, Zosky and Krishnamoorthy [9] proposed to substitute the plasma etching with a simpler chemical etching method based on the partial dissolution of the PC membrane in suitable solvent mixtures. It was reported that after the chemical etching, in spite of the expected increase of active area, double layer charging current did not increase significantly with respect to 2D-NEEs. On the other hand, it was reported that the faradaic current for a reversible redox probe (e.g., $10 \mathrm{mM} \alpha$-methylferrocenemethanol) increases with the etching of the NEE surface.

Notwithstanding the interesting results presented in these papers [7-9], the preliminary explanation of the observed phenomena appears somewhat arguable. Indeed, the effects that a high density of metal nanowires (approximately $6 \times$ $10^{8}$ nanofibers $/ \mathrm{cm}^{2}[1]$ ), and consequently also the overlap of the diffusion layers $[1,4]$ should have on the electrochemical response of these 3D-NEEs, were not taken into proper account, nor discussed.

This prompted us to undertake the present study with the aim to obtain new and precise information on the factors influencing the voltammetric responses at 3D-NEEs, in particular as far as faradaic peak currents and double layer charging currents are concerned. To this aim, we studied the electrochemical behavior at 3D-NEEs of diffusing redox species, characterized by fast or slow electron transfer kinetics, as well as of redox probes adsorbed on gold surfaces. Finally, in order to get preliminary information about the possible use of 3D-NEEs for biosensors development, we studied voltammetric responses of an electrocatalytic chain composed of an adsorbed redox mediator, $\mathrm{NADH}$ and glucose dehydrogenase.

\section{Experimental}

\subsection{Materials and Apparatus}

Polycarbonate filtration membranes (SPI-Pore, $47 \mathrm{~mm}$ filter diameter, $6 \mu \mathrm{m}$ filter thickness) with a nominal pore diameter of $30 \mathrm{~nm}$ and coated with the wetting agent polyvinylpyrrolidone were used as the templates to prepare the NEEs. Commercial gold electroless plating solution (Oromerse Part B, Technic Inc.) was diluted (40 times with water) prior to use.

(Ferrocenylmethyl)dimethylamine (Aldrich) was reacted with methyl iodide to form the quaternary ammonium iodide [10]. This was then converted to (ferrocenylmethyl) trimethylammonium hexafluorophosphate $\left(\mathrm{FA}^{+} \mathrm{PF}_{6}^{-}\right)$using $\mathrm{AgPF}_{6}$.

Phosphomolybdic acid, $\mathrm{H}_{3} \mathrm{PMo}_{12} \mathrm{O}_{40}$, (PMA) was purchased from Sigma; Tris buffer, calcium chloride dihydrate and glucose were purchased from Merck and Sigma, respectively, and used as received. Glucose solutions were left $12 \mathrm{~h}$ for equilibration before use. Tris buffer was prepared by dissolving the adequate amount of compound and adjusting to $\mathrm{pH} 8$ by addition of $\mathrm{HNO}_{3}$.

(4-Carboxy-2,5,7-trinitro-9-fluorenylidene)malononitrile (TNFM) was prepared according to the literature [11].

The reduced form of $\beta$-nicotinamide adenine dinucleotide (NADH) was purchased as the sodium salt with $98 \%$ purity (Sigma). NAD ${ }^{+}$was also obtained from Sigma with $99 \%$ purity. Glucose dehydrogenase from Bacillus megaterium (Sigma) had an activity of 50-150 units per milligram.

All other reagents were of analytical grade and were used as received. Purified water was obtained using a Milli-Ro plus Milli-Q (Millipore) water purification system.

All electroanalytical measurements were carried out at room temperature $\left(22 \pm 1^{\circ} \mathrm{C}\right)$ using a three-electrode single-compartment cell equipped with a platinum coil counter electrode and an $\mathrm{Ag} / \mathrm{AgCl}$ ( $\mathrm{KCl}$ saturated) reference electrode. All potential values are referred to this reference electrode. A CH660A or a Autolab PG-STAT 10 potentiostat controlled via PC by their own software were used for voltammetric measurements.

\subsection{Preparation of the Nanoelectrode Ensembles}

The 2D-NEEs were prepared using the procedures described previously $[1,3]$ slightly modified as follows: after wetting for $2 \mathrm{~h}$ in methanol, the polycarbonate template membrane was sensitized with $\mathrm{Sn}^{2+}$ by immersion into a solution that was $0.026 \mathrm{M}$ in $\mathrm{SnCl}_{2}$ and $0.07 \mathrm{M}$ in trifluoroacetic acid in 50:50 methanol-water for $5 \mathrm{~min}$. After rinsing with methanol for $45 \mathrm{~min}$, the sensitized membrane was immersed for $10 \mathrm{~min}$ in $0.029 \mathrm{M} \mathrm{Ag}\left[\left(\mathrm{NH}_{3}\right)_{2}\right] \mathrm{NO}_{3}$. The membrane was then immersed into the Au plating bath which was $7.9 \times 10^{-3} \mathrm{M}$ in $\mathrm{Na}_{3} \mathrm{Au}\left(\mathrm{SO}_{3}\right)_{2}, 0.127 \mathrm{M}_{\text {in }} \mathrm{Na}_{2} \mathrm{SO}_{3}$. After waiting $30 \mathrm{~min}, 0.625 \mathrm{M}$ formaldehyde was added to the plating bath; this delay time was introduced here since it allows one to separate the formation of the first gold nuclei 
(produced by galvanic displacement of metallic $\mathrm{Ag}^{\circ}$ nuclei with $\mathrm{Au}^{\circ}$ nuclei) from the following catalytic growth of these nuclei by further gold deposition caused by formaldehyde. The temperature of the bath was $0-2{ }^{\circ} \mathrm{C}$. Electroless deposition was allowed to proceed for $15 \mathrm{~h}$, after which an additional 0.3 $\mathrm{M}$ formaldehyde was added. Deposition was continued for another $9 \mathrm{~h}$, after which the membrane was rinsed with water and immersed in $10 \% \mathrm{HNO}_{3}$ for $12 \mathrm{~h}$. The membrane was then rinsed again with water and dried. For the final assembly of the NEEs, see previously published procedures [1,12].

The geometric area, $A_{\text {geom }}$, of the $\operatorname{NEE}\left(0.07 \mathrm{~cm}^{2}\right)$ is determined by the diameter $(3 \mathrm{~mm})$ of a hole punched in the insulating tape that covers the upper face (peeled) of the NEE [1].

\subsection{Etching Procedures}

3D-NEEs were obtained from 2D-NEEs by two different etching procedures: one with a $\mathrm{O}_{2} / \mathrm{Ar}$ plasma [6] and the other using as chemical etching agent a solvent mixture of dichloromethane and ethanol [9]. However, the $\mathrm{CH}_{2} \mathrm{Cl}_{2} / \mathrm{C}_{2}$ $\mathrm{H}_{5} \mathrm{OH}$ ratio used by us was dramatically lower than the one used by other authors [9] (see below).

\subsubsection{Plasma Etching}

The surface of a 2D-NEE was exposed to a $\mathrm{O}_{2} / \mathrm{Ar}$ plasma using a Plasma Asher system (EMITECH K1050X) with the following experimental parameters: power $100 \mathrm{~W}$, flow rate $\mathrm{O}_{2}=30 \mathrm{~cm}^{3} \mathrm{~min}^{-1}$, flow rate $\mathrm{Ar}=10 \mathrm{~cm}^{3} \mathrm{~min}^{-1}$; typical etching time $=30 \mathrm{~s}$.

\subsubsection{Chemical Etching}

2D-NEEs were dipped in a solvent mixture of 1:9 dichloromethane-ethanol for a few seconds (namely 2, 5 and $10 \mathrm{~s}$ ) and then dipped in pure ethanol to stop the etching process; finally, they were abundantly rinsed with water.

Note that dichloromethane acts as the etching agent for $\mathrm{PC}$, while ethanol is used to dilute $\mathrm{CH}_{2} \mathrm{Cl}_{2}$ in order to reduce its etching power, thus allowing one to achieve a better control of the length of the exposed nanowires.

\section{Results and Discussion}

\subsection{Characterization of the Etched NEEs}

At first, we critically compared and optimized the two etching procedures, i.e., oxygen-plasma [6] vs. chemical etching [9]. Figure 1 reports scanning electron micrographs (SEM) of the surface of the NEEs before (Fig. 1A) and after controlled etching with $\mathrm{O}_{2}$ plasma (Fig. 1B) and with $\mathrm{CH}_{2}$ $\mathrm{Cl}_{2} / \mathrm{C}_{2} \mathrm{H}_{5} \mathrm{OH}$ (Fig. 1C). The heads of the fibers, which appear in Figure $1 \mathrm{~B}$, indicate that the use of $\mathrm{O}_{2}$ plasma leads to the successful etching of the external layer of the PC membrane.
A)

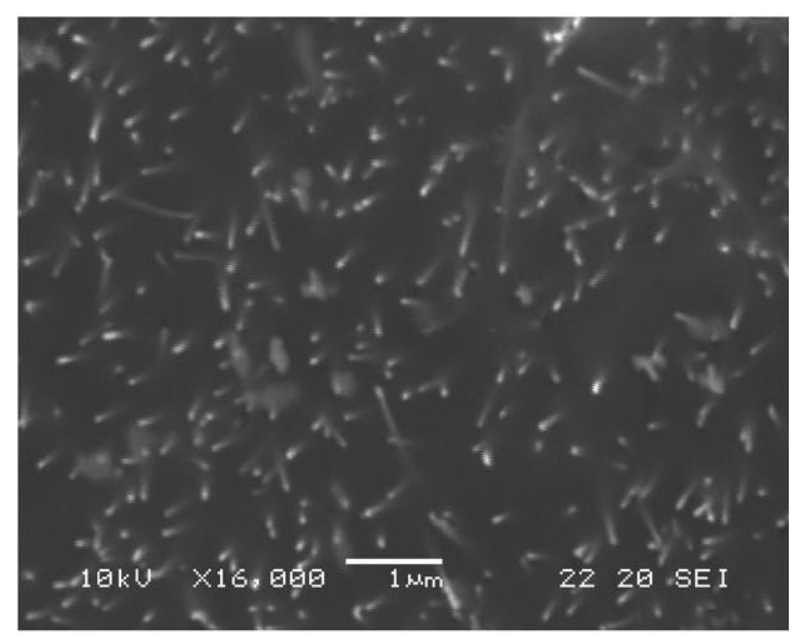

B)

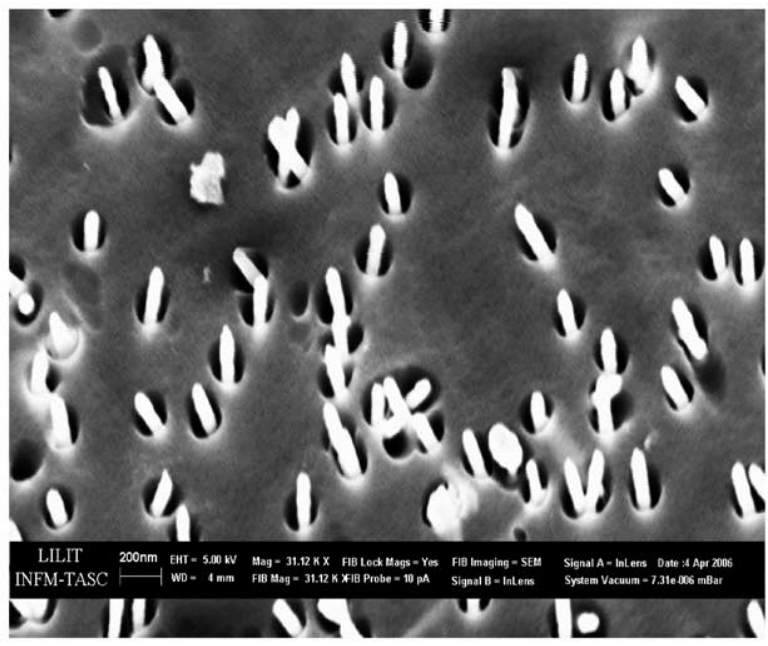

C)

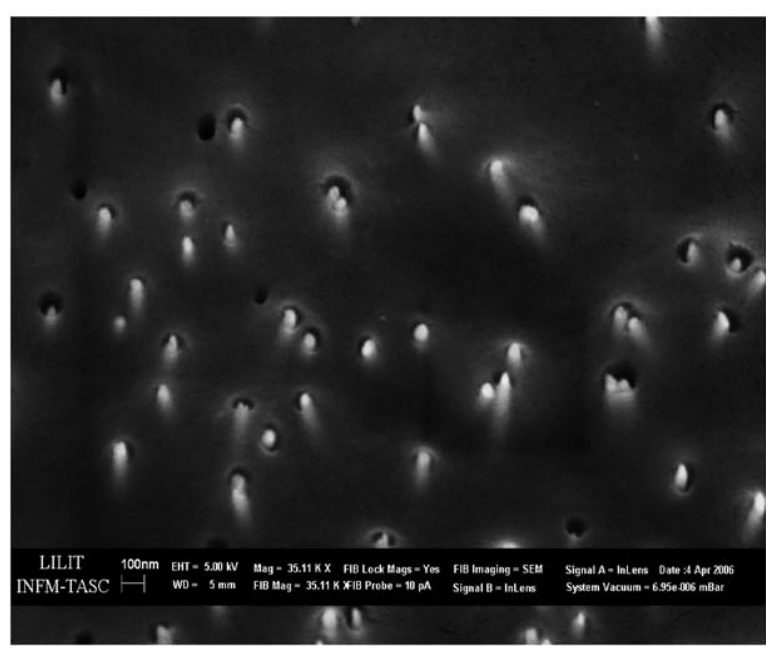

Fig. 1. SEM (A) and FE-SEM (B, C) images of a NEE: A) after gold electroless deposition and peeling the gold from the outer face of the membrane; B) after etching with $\mathrm{O}_{2} / \mathrm{Ar}$ plasma for $30 \mathrm{~s}$; C) after chemical etching with $1: 9 \mathrm{CH}_{2} \mathrm{Cl}_{2} / \mathrm{C}_{2} \mathrm{H}_{5} \mathrm{OH}$ for $5 \mathrm{~s}$.

Preliminary results indicated that $30 \mathrm{~s}$ etching time is enough for exposing the fibers to a length of about 
$200 \mathrm{~nm}$, which is a length suitable for the fabrication of 3DNEEs sensors. However, SEM images show that rather large holes were created around the gold nanowires, probably caused by high local heating at the fibers during the plasma etching process. This has been described previously by Martin et al. [6] who reported also the progressive shrinking of the NEE with increasing etching time as a consequence of plasma-induced heating of the membrane. The presence of the holes around the fibers is undesirable from an electrochemical viewpoint, since it breaks the sealing between the gold nanofibers and the PC membrane. This limits dramatically the possibility to use plasma etched NEEs for electrochemical studies because of the big uncertainty and difficulty in controlling the total active area of the ensemble.

Typical 3D-NEEs obtained after the chemical etching are shown in Figure 1C. The removal of the outer PC layers by dilute $\mathrm{CH}_{2} \mathrm{Cl}_{2}$ is quite homogenous, equally affecting the whole observed surface. Some slits are still present around the fibers, however, they are much smaller compared to those observed after plasma etching. Heating of the chemically etched 3D-NEEs at temperatures higher than the PC glass transition temperature $\left(150^{\circ} \mathrm{C}\right)$ further decreased the dimensions of these small slits below the resolving power of the SEM images (not shown).

Figure 2 shows the cyclic voltammograms (CVs) recorded in pure supporting electrolyte at $100 \mathrm{mV} / \mathrm{s}$ with NEEs before (curve a) and after chemical etching, using different etching times (curves b-d). From these voltammograms, increments in double layer charging currents due to etching can be easily calculated by known methods (see [13], page 18). Data listed in the first line of Table 1, show that these increments scale with the etching time, as expected on the basis of Equation 4, which correlates double layer charging current with the active area of NEEs $[1,14]$ :

$i_{\mathrm{C}}=v C_{\mathrm{dl}} A_{\mathrm{act}}$ where $C_{\mathrm{dl}}$ is the double layer capacitance of gold and $v$ is the scan rate.

Background CVs with plasma etched NEEs (not shown) point out a much larger increase in capacitive current, that is approximately 3-times larger than the value expected on the basis of the length of the Au nanofibers protruding out of the PC surface after the etching (see Fig. 1B). The large disagreement between experimental and expected data for plasma etched NEEs, confirms the difficulty to achieve full control of the active area by this etching method. For this reason, only chemical etching was used in the following experiments to prepare 3D-NEEs with well controlled active area.

\section{2. $\mathrm{FA}^{+}$at 3D-NEEs}

Since the main goal of this work was the detailed understanding of the factors influencing voltammetric responses at 3D-NEEs, a comparison of signals obtained using redox species characterized by fast and slow heterogeneous electron transfer kinetics respectively was performed. $\mathrm{FA}^{+}$ was chosen as a typical water soluble redox probe characterized by fast heterogeneous electron transfer kinetics $[1,2$, 15]. Figure $3 \mathrm{~A}$ shows the CVs recorded in the same $10 \mu \mathrm{M}$ $\mathrm{FA}^{+}$solution, using three different NEEs before chemical etching. Peak shaped voltammograms are obtained with features in agreement with previous CVs recorded at 2DNEEs operating under total overlap conditions $[1,2,16]$; the similarity between the three CV patterns obtained at three different NEEs confirms a very satisfactory reproducibility in the preparation procedure. Figure $3 \mathrm{~B}$ shows the CVs recorded in the same solution, but using $3 \mathrm{D}$-NEEs etched in $\mathrm{CH}_{2} \mathrm{Cl}_{2} / \mathrm{C}_{2} \mathrm{H}_{5} \mathrm{OH}$ for 2, 5 and $10 \mathrm{~s}$.

These CVs, together with relevant data listed in Table 1, indicate that faradaic peak currents are practically unin-

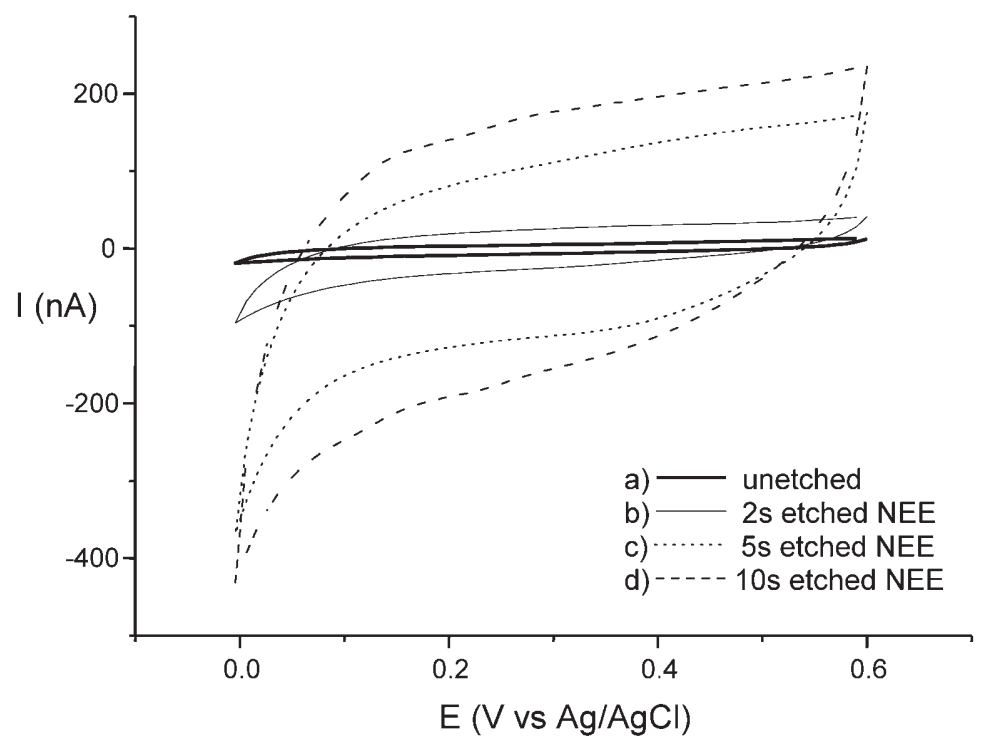

Fig. 2. Background $\mathrm{CVs}$ in $1 \mathrm{mM} \mathrm{KNO}$ recorded at $100 \mathrm{mV} / \mathrm{s}$ : a) with an unetched $\mathrm{NEE}$ and with $\mathrm{NEEs}_{3}$ etched with $1: 9 \mathrm{CH}_{2} \mathrm{Cl}_{2} / \mathrm{C}_{2} \mathrm{H}_{5}$ $\mathrm{OH}$ for $2 \mathrm{~s}(\mathrm{~b}), 5 \mathrm{~s}(\mathrm{c}), 10 \mathrm{~s}(\mathrm{~d})$. 

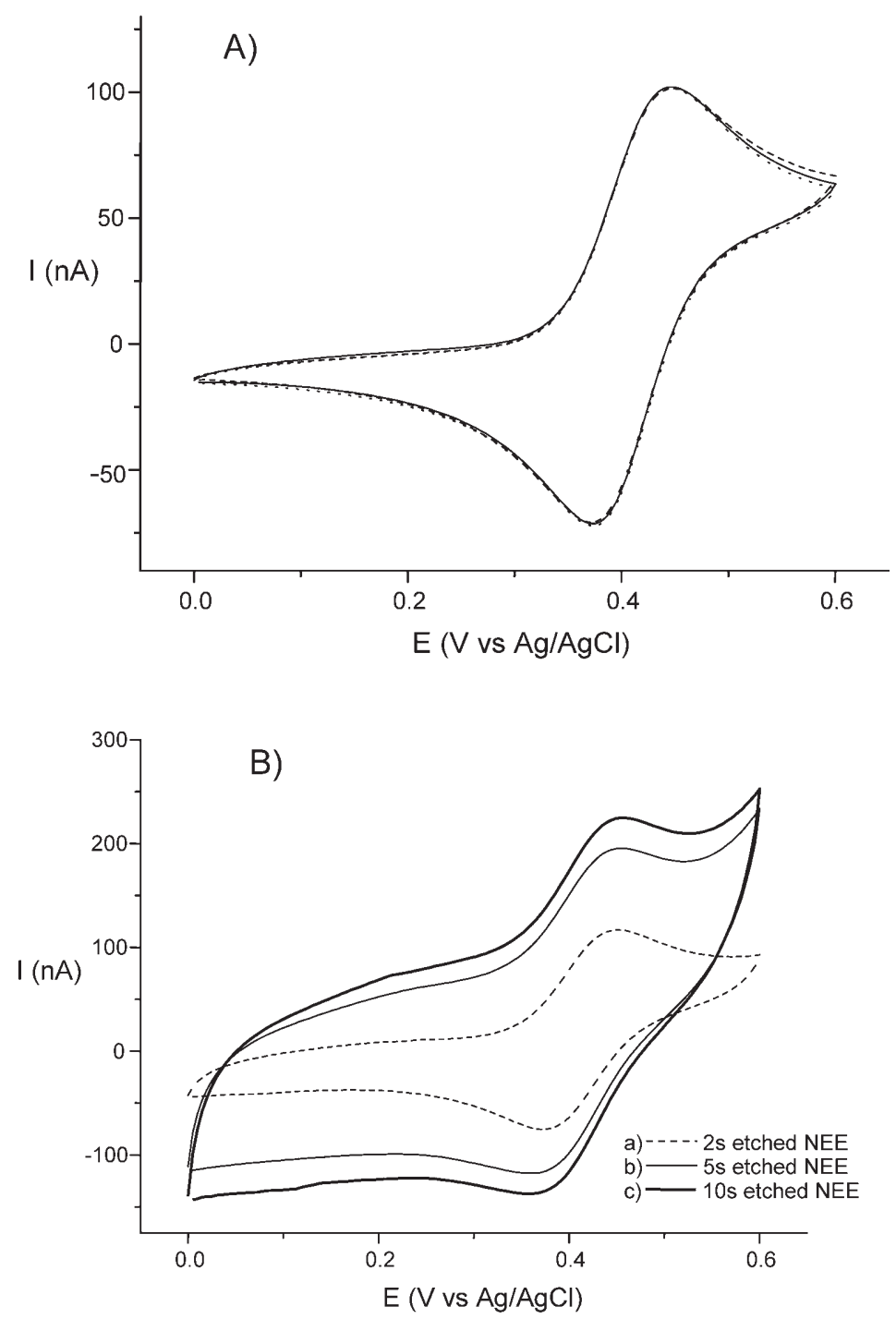

Fig. 3. $\mathrm{CVs}$ of $10 \mu \mathrm{M} \mathrm{FA}^{+}$in $1 \mathrm{mM} \mathrm{KNO}_{3}$ recorded at $50 \mathrm{mV} / \mathrm{s}$ : A) with three different unetched NEEs; B) with NEEs etched with 1:9 $\mathrm{CH}_{2} \mathrm{Cl}_{2} / \mathrm{C}_{2} \mathrm{H}_{5} \mathrm{OH}$ for $2 \mathrm{~s}$ (a), $5 \mathrm{~s} \mathrm{(b),} 10 \mathrm{~s}$ (c).

Table 1. Dependence on the etching time (in $1: 9 \mathrm{CH}_{2} \mathrm{Cl}_{2} / \mathrm{C}_{2} \mathrm{H}_{5}$ $\mathrm{OH})$ for the increase in double layer charging current and faradaic peak current, obtained from the CVs in Figures 2 and 3, respectively, with respect to CVs recorded at unetched NEEs.

\begin{tabular}{llll}
\hline & \multicolumn{3}{l}{ Etching time } \\
\cline { 2 - 3 } $2 \mathrm{~s}$ & $5 \mathrm{~s}$ & $10 \mathrm{~s}$ \\
\hline
\end{tabular}

Increase of capacitive current $\left(i_{\mathrm{C}}\right) 8$ times 25 times 45 times Increase of faradaic current $\left(i_{\mathrm{F}}\right) \quad 0.9$ times 0.9 times 0.9 times

fluenced by the etching process, while double layer capacitive currents are. Both at unetched and etched NEEs, peak currents for $\mathrm{FA}^{+}$oxidation increase linearly with the square root of the scan rate, with slopes of the plots (not shown) independent of the etching time.
The observation that the faradaic currents do not change significantly with the etching time can be explained taking into account that the redox species studied here undergo a fast electron transfer process, characterized by a quite high value for the true heterogeneous rate constant $k^{\circ}=0.56$ [15]. Since NEEs behave as PBE, one has to take into account that the true kinetic constant should be substituted by an apparent kinetic constant given by Equation 2 . However, for a fast redox couple such as $\mathrm{FA}^{+}$, the influence of the change of $k_{\text {app }}^{\circ}$ values by changing $f$ cannot be appreciated experimentally at the scan rates used here $(100 \mathrm{mV} / \mathrm{s}$ or lower) at $30 \mathrm{~nm}$ NEEs [1]. Under total overlap conditions, for a fast redox species, the faradaic current is indeed controlled by linear diffusion, so that it remains proportional to the overall geometric area of the ensemble $[4,17]$, independently from the fact that the individual nanoelectrodes are etched or unetched. 


\subsection{Electrochemistry of Fast vs. Slow Redox Couples at 3D-NEES}

Following the guideline described above, the reduction of $\mathrm{H}_{2} \mathrm{O}_{2}$, occurring according to Reaction 5:

$\mathrm{H}_{2} \mathrm{O}_{2}+2 \mathrm{H}^{+}+2 \mathrm{e}^{-} \rightarrow 2 \mathrm{H}_{2} \mathrm{O}$

was chosen as a typical electrochemical process characterized by a slow heterogeneous electron transfer kinetics. Note that it was theoretically predicted by Amatore $[4,17]$ that voltammetric responses at PBEs (and, therefore, at NEEs as well) should change dramatically when kinetic control, instead of simple diffusion is involved. This is because the heterogeneous kinetics limitation causes a considerable torsion of the lines of flux near each nanoelectrode element, thus imposing a local rate of diffusion considerably larger than the one far from each electrode [17]; under these conditions, each nanoelectrode should behave as an individual element, as far as heterogeneous kinetics is concerned.

Figure 4 shows the CVs relevant to $\mathrm{H}_{2} \mathrm{O}_{2}$ reduction at unetched and etched NEEs. Note that in order to record useful signals, a high $\mathrm{H}_{2} \mathrm{O}_{2}$ concentration and a slow scan rate had to be employed.

These data show that currents recorded at the cathodic limit of the potential window explored, depend strongly on the etching time of the NEE. At an unetched NEE, a very small, almost negligible, cathodic current is observed at 0 Volt, which increases gradually with NEEs etched for progressively longer time (see Fig. 4).

On the basis of Equation 2, the etching reflects an increase of $A_{\text {act }}$ and concomitantly of $\mathrm{f}$ and $k_{\text {app }}{ }^{\circ}$. This explains why the cathodic current for $\mathrm{H}_{2} \mathrm{O}_{2}$ reduction (slow process) increases when using progressively more etched NEEs; $k_{\text {app }}{ }^{\circ}$ increases, in fact, significantly with the active area and now, since the electron transfer process is kineti- cally controlled, such an effect causes dramatic changes in the CVs. The $\mathrm{H}_{2} \mathrm{O}_{2}$ cathodic current increases according to the ratio $1: 10: 25: 55$ for NEEs etched for $0,2,5$ and $10 \mathrm{~s}$, respectively, which reflects the increase in active area caused by the etching process (see increases in capacitive currents in Table 1).

Note that the difference in behavior between fast and slow redox couples here discussed for NEEs is similar to what has been observed very recently for macroporous electrodes [18]. In the latter case, the key point was the possibility to control changes in surface area (surface roughness) on a microscale and to show that they can be detected only when using suitably slow redox couples.

\subsection{Electrochemistry of Adsorbed Species at 3D-NEEs}

For many electroanalytical applications the surface of electrodes in general, and NEEs in particular [19, 20] can be modified either with catalysts, mediators or molecular recognition elements. Therefore the electrochemical behavior of surface-confined redox species was also examined here on the etched NEEs. With respect to the present study this is particularly interesting since, in contrast to diffusing species, signals of adsorbed redox probes, should always depend on the active area that is, for 3D-NEEs, on the etching time.

Figure 5 shows the CVs recorded at $50 \mathrm{mV} / \mathrm{s}$ for an unetched NEE and a 3D-NEE dipped in $5 \mathrm{mM}$ phosphomolybdic acid, rinsed with water and transferred into pure supporting electrolyte. The voltammograms are characterized by two reversible processes which correspond to the following reactions:

$$
\begin{aligned}
& \mathrm{PMo}_{12} \mathrm{O}_{40}^{3-}+2 \mathrm{e}^{-} \rightleftharpoons \mathrm{PMo}_{12} \mathrm{O}_{40}^{5-} \\
& \mathrm{PMo}_{12} \mathrm{O}_{40}^{5-}+2 \mathrm{e}^{-} \rightleftharpoons \mathrm{PMo}_{12} \mathrm{O}_{40}^{7-}
\end{aligned}
$$

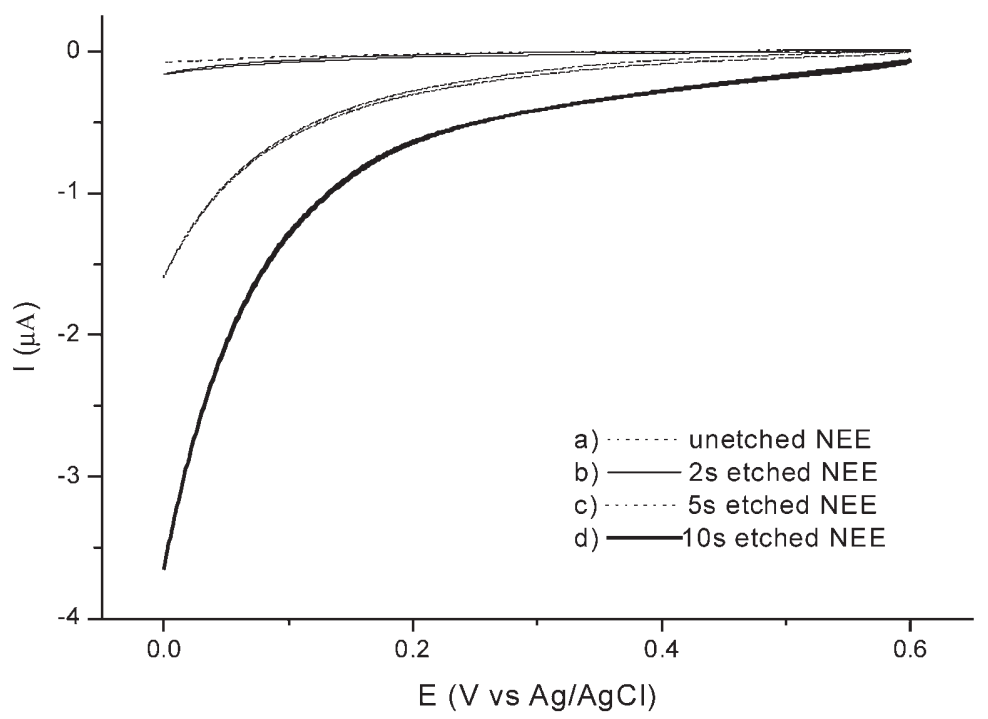

Fig. 4. $\mathrm{CVs}$ recorded in $0.3 \mathrm{M} \mathrm{H}_{2} \mathrm{O}_{2}, 0.5 \mathrm{M} \mathrm{H}_{2} \mathrm{SO}_{4}$ at $10 \mathrm{mV} / \mathrm{s}$ : a) with an unetched $\mathrm{NEE}$ and with $\mathrm{NEEs}$ etched with $1: 9 \mathrm{CH}_{2} \mathrm{Cl}_{2} / \mathrm{C}_{2} \mathrm{H}_{5}$ $\mathrm{OH}$ for $2 \mathrm{~s}(\mathrm{~b}), 5 \mathrm{~s}(\mathrm{c}), 10 \mathrm{~s}(\mathrm{~d})$. 


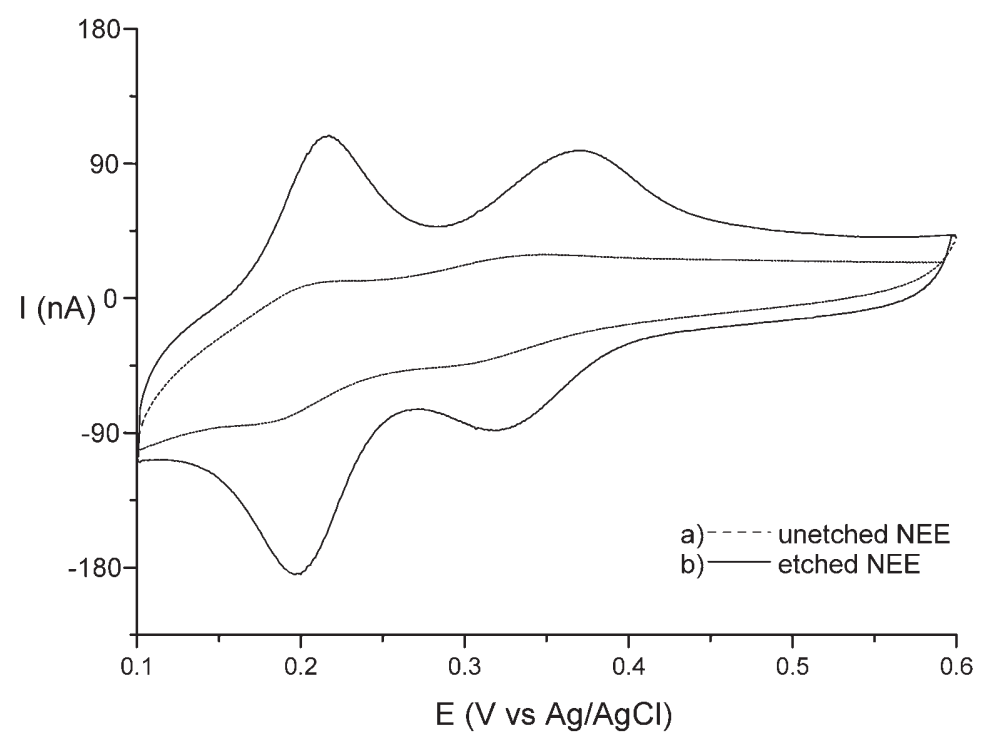

Fig. 5. CVs recorded in $0.5 \mathrm{M} \mathrm{H}_{2} \mathrm{SO}_{4}$ at $50 \mathrm{mV} / \mathrm{s}$ after dipping the working electrode in $5 \mathrm{mM} \mathrm{H}_{3} \mathrm{PMo}_{12} \mathrm{O}_{40}$ for $1 \mathrm{~h}$, rinsing and transfer into pure supporting electrolyte for an unetched NEE and a NEE etched with $1: 9 \mathrm{CH}_{2} \mathrm{Cl}_{2} / \mathrm{C}_{2} \mathrm{H}_{5} \mathrm{OH}$ for $10 \mathrm{~s}$.

The evidence that the electrochemical reduction of PMA is detected even after transfer to pure supporting electrolyte, agrees with literature reports [21] which indicate that PMA adsorbs on gold surfaces. Actually, the PMA signal at unetched NEEs is very small and barely detectable from the background current, while this signal increases dramatically for the etched NEE. This agrees with the occurrence of a surface confined process and with the increase in active area caused by the etching.

Figure 6 shows that at etched NEEs, reduction peak currents depend linearly on the scan rate, confirming once again that signals refer to an adsorbed species [13].
The charge $(Q)$ associated with the two reduction peaks can be obtained by integration of the peak area. Data obtained at NEEs chemically etched for different times, are listed in Table 2, together with the number of moles adsorbed $(m)$ calculated by Equation 8:

$m=Q / n F$

where $n$ is the number of electrons exchanged (in this case four) and $F$ is the Faraday constant.

Both, charge and number of moles adsorbed scale with the etching time, once again confirming the possibility to control

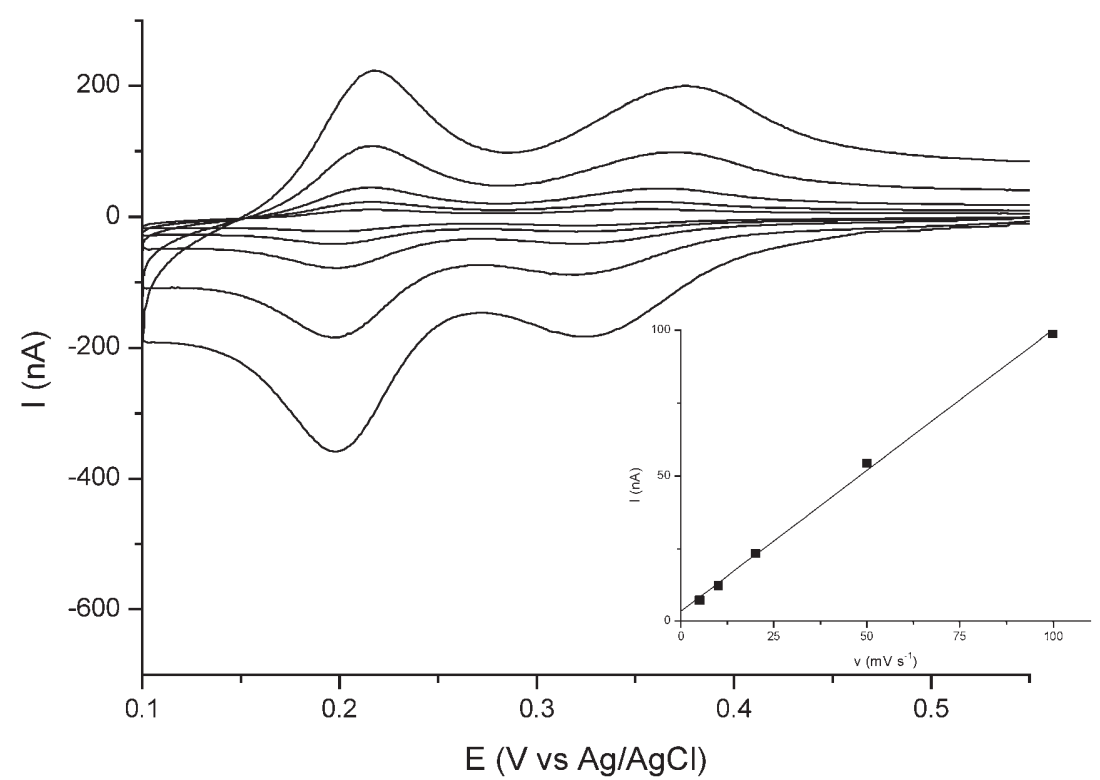

Fig. 6. CVs recorded at different scan rates in $0.5 \mathrm{M} \mathrm{H}_{2} \mathrm{SO}_{4}$ at a $\mathrm{NEE}$ etched with $1: 9 \mathrm{CH}_{2} \mathrm{Cl}_{2} / \mathrm{C}_{2} \mathrm{H}_{5} \mathrm{OH}$ for 10 s; the working electrode was dipped in $5 \mathrm{mM} \mathrm{H}_{3} \mathrm{PMo}_{12} \mathrm{O}_{40}$ for $1 \mathrm{~h}$, rinsed with water and transferred into pure supporting electrolyte; scan rates 5, 10, 20, 50 $100 \mathrm{mV} / \mathrm{s}$, from the smaller to the larger peak currents CVs. Insert: peak current vs. scan rate plot, relevant to the first reduction peak. 
Table 2. Dependence on the etching time (in 1:9 $\mathrm{CH}_{2} \mathrm{Cl}_{2} / \mathrm{C}_{2} \mathrm{H}_{5}$ $\mathrm{OH})$ for the charge $(Q)$ and number of moles adsorbed $(\mathrm{m})$, obtained by integration of the reduction peak currents recorded at NEEs dipped in $5 \mathrm{mM} \mathrm{H}_{3} \mathrm{PMo}_{12} \mathrm{O}_{40}$ for $1 \mathrm{~h}$, rinsed with water and transferred into $0.5 \mathrm{M} \mathrm{H}_{2} \mathrm{SO}_{4}$.

\begin{tabular}{llll}
\hline & \multicolumn{2}{l}{ Etching time } & \\
\cline { 2 - 4 } & $2 \mathrm{~s}$ & $5 \mathrm{~s}$ & $10 \mathrm{~s}$ \\
\hline$Q(\mathrm{C})$ & $1.5 \times 10^{-8}$ & $4.2 \times 10^{-8}$ & $6.9 \times 10^{-8}$ \\
$m(\mathrm{pmol})$ & $3.9 \times 10^{-2}$ & $1.08 \times 10^{-1}$ & $1.80 \times 10^{-1}$ \\
\hline
\end{tabular}

the active area of the NEE by controlling the etching time and, consequently, the amount of adsorbed redox probe.

Not only inorganic species, like PMA, can be easily immobilized on the surface of 3D-NEEs, but it was also possible to demonstrate the usefulness of 3D-NEEs, for the adsorption of organic electroactive species suitable for example as mediators in electrochemical biosensors. As a model system the adsorption and electron shuttling capabilities of a nitrofluorenone derivative, namely 4-carboxy 2,5,7-trinitro-9-fluorenylidene-malononitrile, has been examined.

The 3D-NEE was dipped in $1 \mathrm{mM}$ TNFM solution and then transferred into pure supporting electrolyte. The adsorption and activation of TNFM proceeds via the two following steps [22]:

$$
\begin{aligned}
& \mathrm{ArNO}_{2}+4 \mathrm{e}^{-}+4 \mathrm{H}^{+} \rightarrow \mathrm{ArNHOH}+\mathrm{H}_{2} \mathrm{O} \\
& \mathrm{ArNHOH} \rightleftharpoons \mathrm{ArNO}+2 \mathrm{e}^{-}+2 \mathrm{H}^{+}
\end{aligned}
$$

with Ar as a symbol for the aromatic moiety of the molecule.

The first irreversible process (Reaction 10) proceeds at potentials more negative than approximately $-350 \mathrm{mV}$, while the second reversible process takes place, at $\mathrm{pH} 7$, with an $E_{1 / 2}$ of about $-50 \mathrm{mV}$. Note that Reaction 10 is required for the preactivation and assisted adsorption of the mediator, while Reaction 11 is a process which can be exploited for the electrocatalytic oxidation of NADH [23]. The thin line pattern in Figure 7A shows the CV recorded in the potential range of Reaction 11 for a 3D-NEE on which TNFM was adsorbed and preactivated. A small signal, relevant to Reaction 11, is indeed detected, although it is not significantly resolved from the background current. Note that such a signal is undetectable at unetched NEEs (not shown).

As shown by the thick line in the CV of Figure 7A, the CV pattern of the mediator modified 3D-NEE changes dramatically when NADH is added to the buffer solution. A well resolved wave is now observed, corresponding to the electrocatalytic oxidation of NADH caused by activated TNFM [23].

As expected, no electrocatalysis was observed for functionalized 3D-NEE when $\mathrm{NAD}^{+}$was used instead of $\mathrm{NADH}$ (not shown); moreover, the voltammetric pattern did not change after the addition of $\mathrm{NAD}^{+}$and GDH (see thin line in Fig. 7B). However, as shown by the thick line of
Figure 7B, the addition of glucose causes again a catalytic current.

Under the latter experimental conditions, the following reactions sequence is indeed operating [22]:

$$
\begin{aligned}
& \mathrm{GDH}_{\mathrm{ox}}+\text { Glucose } \rightarrow \mathrm{P}+\mathrm{GDH}_{\mathrm{red}} \\
& \mathrm{GDH}_{\mathrm{red}}+\mathrm{NAD}^{+} \rightarrow \mathrm{GDH}_{\mathrm{ox}}+\mathrm{NADH} \\
& \mathrm{NADH}+\mathrm{M}_{\mathrm{ox}} \rightarrow \mathrm{NAD}^{+}+\mathrm{M}_{\mathrm{red}} \\
& \mathrm{M}_{\mathrm{red}} \rightarrow \mathrm{M}_{\mathrm{ox}}+2 \mathrm{e}^{-}+2 \mathrm{H}^{+}
\end{aligned}
$$

with $\mathrm{P}$ being the reaction product and $\mathrm{M}$ the mediator.

Under such conditions, NADH is produced at the electrode/solution interface by Reaction 13, thus triggering indirectly the electrochemical signal of the mediator by Reaction 15.

These preliminary results confirm the effective adsorption of the mediator on the nanowires and the possibility to apply 3D-NEEs in electrochemical biosensors which employ surface confined redox mediators with the perspective to benefit from an improved signal/background current ratio.

\section{Conclusions}

3D-NEEs are powerful electrode systems with a high active surface suitable for functionalization and extreme miniaturization. In contrast to previous preliminary observations reported in the very recent literature [8-9], the results of the present study demonstrated that the etching really causes an increase in capacitive current, which is proportional to the increase in active area. Faradaic peak currents at 3D-NEEs can change dramatically with the heterogeneous electron transfer kinetics. For fast redox couples, faradaic currents depend on the overall geometric area of the ensemble (nanoelectrodes and insulator between them), so that voltammetric peak currents remain almost unaffected by the partial etching of the template membrane causing a negligible increase of $A_{\text {geo }}$; this is not true for slow redox probes for which faradaic currents are significantly dependent on changes of the active area (area of the nanoelectrodes alone). Electrochemical responses at 3D-NEEs agree, indeed, with the theoretical model developed some years ago for PBEs by Amatore et al. [4]. For very fast redox couples, such as $\mathrm{FA}^{+}$, faradaic currents are insensitive to the etching since the heterogeneous kinetics is always very fast and total overlap conditions remain always operative. On the other hand, for redox couples characterized by slow heterogeneous kinetics, each nanoelectrode behaves individually and, because of strong kinetic limitations, faradaic currents depend significantly on the increase in active area caused by the etching. This is true for diffusing electroactive species while voltammetric responses for redox probes adsorbed on the nanoelectrode surface depend always on the active area. 

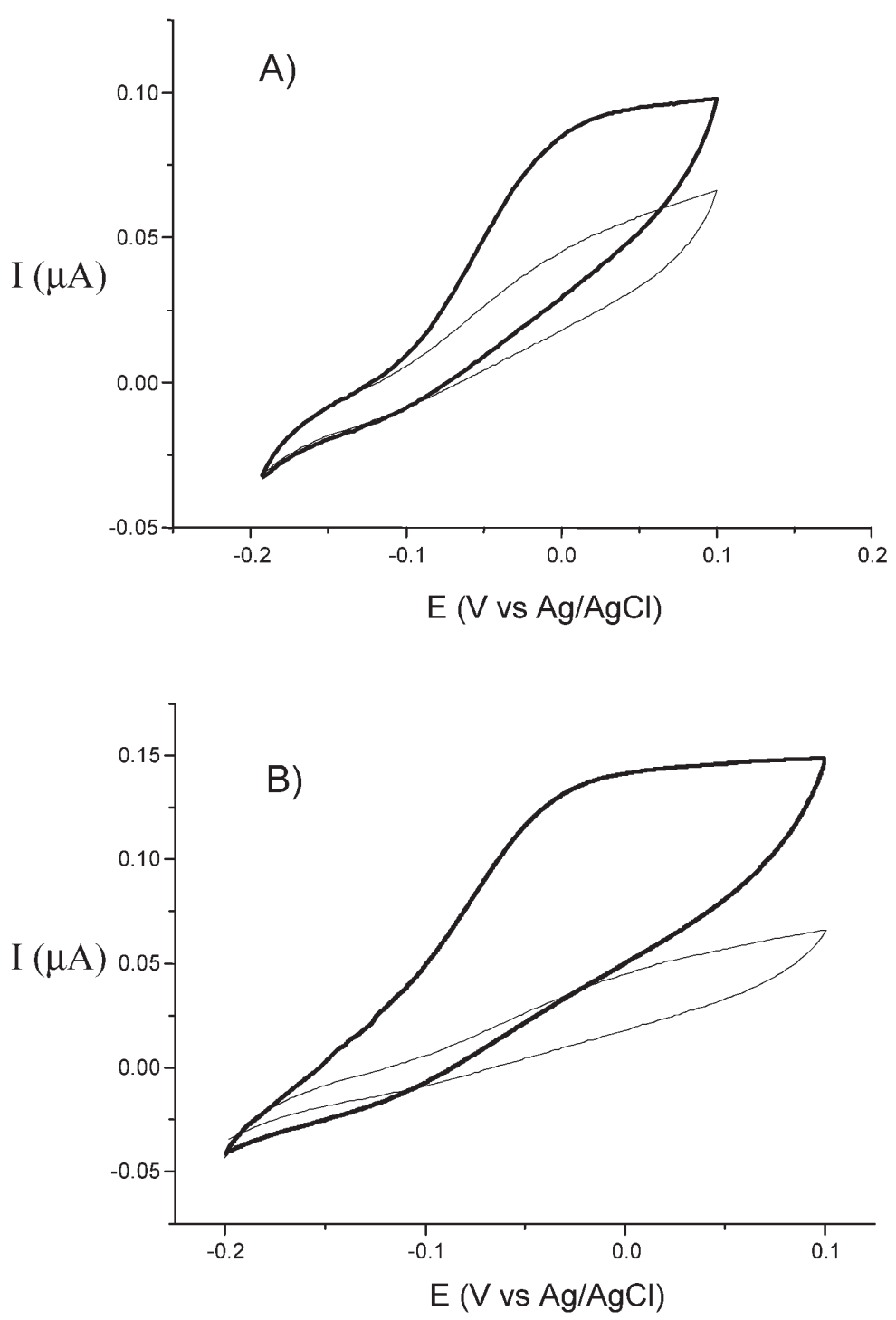

Fig. 7. CVs recorded at $100 \mathrm{mV} / \mathrm{s}$ with a $\mathrm{NEE}$ etched in $1: 9 \mathrm{CH}_{2} \mathrm{Cl}_{2} / \mathrm{C}_{2} \mathrm{H}_{5} \mathrm{OH}$, dipped for $2 \mathrm{~h}$ in $1 \mathrm{mM}$ 4-carboxy-2,5,7-trinitro-9fluorenylidene-malononitrile, rinsed with water and transferred into $0.2 \mathrm{M} \mathrm{CaCl}_{2}, 0.1 \mathrm{M}$ Tris buffer solution (pH 8): A) before (thin line), and after the addition of $0.5 \mathrm{mM} \mathrm{NADH}$ (thick line); B) after the addition of $3.2 \mathrm{mM} \mathrm{NAD}^{+}$and 3 units of GDH (thin line), and $0.2 \mathrm{mM}$ glucose (thick line).

These evidences indicate that the high surface area of 3DNEEs can be best exploited to increase the voltammetric signals for electroactive species: i) that are adsorbed on the nanoelectrodes; ii) that diffuse from the bulk solution, but are characterized by slow heterogeneous electron transfer kinetics.

These aspects, whose relevance for 3D-NEEs was, for the first time, demonstrated here, must be taken into proper account when thinking to use 3D-NEEs in electroanalysis and for the development and optimization of new electrochemical sensors.

\section{Acknowledgements}

Financial support by MIUR (Rome, Cofin 2004) is grateful acknowledged. M. De Leo is thankful to the University of Venice for an international mobility grant. We are grateful to Christian Amatore (ENS, Paris) for helpful discussions and to Stefano Polizzi (University of Venice) and Massimo Tormen (Lilit, Trieste) for SEM and FE-SEM measurements. 


\section{References}

[1] V. P. Menon, C. R. Martin, Anal. Chem. 1995, 67, 1920.

[2] P. Ugo, L. M. Moretto, S. Bellomi, V. P. Menon, C. R. Martin, Anal. Chem. 1996, 68, 4169.

[3] B. Brunetti, P. Ugo, L. M. Moretto, C. R. Martin, J. Electroanal. Chem. 2000, 491, 166.

[4] C. Amatore, J. M. Saveant, D. Tessier, J. Electroanal. Chem. 1983, 147, 39.

[5] P. Ugo, L. M. Moretto, F. Vezzà, ChemPhysChem 2002, 3, 917.

[6] S. Yu, N. Li, J. Wharton, C. R. Martin, Nano Lett. 2003, 3, 815.

[7] R. Gasparac, B. J. Taft, M. A. Lapierre-Devlin, A. D. Lazareck, J. M. Xu, and S. O. Kelly, J. Am. Chem. Soc. 2004, 126, 12270.

[8] M. A. Lapierre-Devlin, C. L. Asher, B. J. Taft, R. Gasparac, M. A. Roberts, S. O. Kelley, Nano Lett. 2005, 5, 1051

[9] K. Krishnamoorthy, C. G. Zoski, Anal. Chem. 2005, 77, 5068.

[10] A. Lombardo, T. I.Bieber, J. Chem. Edu. 1983, 60, 1080.

[11] N. Mano, A. Kuhn, J. Electroanal. Chem. 1999, 477, 79.
[12] P. Ugo, N. Pepe, L. M. Moretto, M. Battagliarin, J. Electroanal. Chem. 2003, 560, 51.

[13] A. J. Bard and L. Faulkner, Electrochemical Methods, Wiley, New York 2000.

[14] F. C. Pereira, L. M. Moretto, M. De Leo, M. V. Boldrin Zanoni, P. Ugo, Anal. Chim. Acta 2006, 575, 16.

[15] E. Sabatani, I. Rubinstein, J. Phys. Chem. B 1987, 91, 6663.

[16] L. M. Moretto, N. Pepe, P. Ugo, Talanta 2003, 62, 1055.

[17] C. Amatore, in Physical Electrochemistry (Ed: I. Rubinstein), Marcel Dekker, New York 1995.

[18] R. Szamocki, S. Reculusa, S. Ravaine, P. N. Bartlett, A. Kuhn, R. Hempelmann, Angew. Chem. Int. Ed. 2006, 45, 1317.

[19] M. Delvaux, S. Demoustier-Champagne, A. Walcarius, Electroanalysis 2004, 16, 190.

[20] M. Delvaux, A. Walcarius, S. Demoustier-Champagne, Biosens. Bioelectron. 2005, 20, 1587.

[21] A. Kuhn, F. C. Anson, Langmuir 1996, 12, 5841.

[22] N. Mano, A. Kuhn, Biosens. Bioelectron. 2001, 16, 653.

[23] N. Mano, A. Thienpont, A. Kuhn, Electrochem. Commun. 2001, 3, 585 . 